\title{
Tubuloglomerular Feedback and Single Nephron Function after Converting Enzyme Inhibition in the Rat
}

\author{
David W. Ploth, James Rudulph, Ronald laGrange, and L. Gabriel Navar, \\ Veterans Administration Medical Center and Department of Medicine, \\ Nephrology Research and Training Center, and Department of Physiology and \\ Biophysics, University of Alabama Medical Center, University Station, \\ Birmingham, Alabama 35294
}

A B S T R A C T Experiments were done in normal rats to assess kidney, single nephron, and tubuloglomerular feedback responses during renin-angiotensin blockade with the converting enzyme inhibitor (CEI) SQ 20881 (E. R. Squibb \& Sons, Princeton, N. Y.) (3 mg/kg, per h). Converting enzyme inhibition was documented by complete blockade of vascular responses to infusions of angiotensin I $(600 \mathrm{ng} / \mathrm{kg})$. Control plasma renin activity was $12.5 \pm 2.7 \mathrm{ng}$ angiotensin $\mathrm{I} / \mathrm{ml}$ per $\mathrm{h}$ (mean \pm SEM) and increased sevenfold with CEI $(n=7)$. There were parallel increases in glomerular filtration rate from $1.08 \pm 0.05$ to $1.26 \pm 0.05 \mathrm{ml} / \mathrm{min}$ and renal blood flow from $6.7 \pm 0.4$ to $7.5 \pm 0.5 \mathrm{ml} / \mathrm{min}$. During CEI infusion absolute and fractional sodium excretion were increased 10-fold. Proximal tubule and peritubular capillary pressures were unchanged. Single nephron glomerular filtration rate (SNGFR) was measured from both proximal and distal tubule collections; SNGFR based only on distal collections was significantly increased by CEI. A significant difference was observed between SNGFR values measured from proximal and distal tubule sites $(6.0 \pm 1.6$ $\mathrm{nl} / \mathrm{min}$ ) and this difference remained unchanged after CEI administration. Slight decreases in fractional absorption were suggested at micropuncture sites beyond the late proximal tubule, whereas early distal tubule flow rate was augmented by CEI. Tubuloglomerular feedback activity was assessed by measuring changes in proximal tubule stop-flow pressure (SFP) or SNGFR in response to alterations in orthograde microperfusion rate from late proximal tubule sites. During control periods, SFP was decreased 11.2 \pm 0.4

This work was presented in part at the Fall American Physiological Society Meetings in Miami, Florida, 1977, and at the VII International Congress of Nephrology in Montreal, Canada, 1978.

Dr. Navar is the recipient of a National Heart and Lung Institute Research Career Development Award.

Received for publication 7 August 1978 and in revised form 27 June 1979. $\mathrm{mm} \mathrm{Hg}$ when the perfusion rate was increased to 40 $\mathrm{nl} / \mathrm{min}$; during infusion of CEI, the same increase in perfusion rate resulted in a SFP decrement of $6.7 \pm 0.5$ $\mathrm{mm} \mathrm{Hg}(P<.001)$. When late proximal tubule perfusion rate was increased from 0 to $30 \mathrm{nl} / \mathrm{min}$, SNGFR was decreased by $15.0 \pm 1.2 \mathrm{nl} / \mathrm{min}$ during control conditions, and by $11.3 \pm 1.3 \mathrm{nl} / \mathrm{min}$ during CEI infusion. Attenuation of feedback responsiveness during CEI was also observed at lower perfusion rates with both techniques. These results indicate that blockade of the renin-angiotensin system with CEI reduces the activity of the tubuloglomerular feedback mechanism which may mediate the observed renal vasodilation.

\section{INTRODUCTION}

Although some of the systemic vascular and renal effects of angiotensin II appear clearly defined (1-3), the intrarenal role of renin and the subsequent generation of angiotensin II in the regulation of glomerular filtration and tubular absorptive function remains a controversial issue. Several recent studies have examined the role of the renin-angiotensin system in the control of autoregulation of kidney hemodynamics (4-7), and although conflicting, these reports have failed to establish a pivotal role for the renin-angiotensin system in the mediation of autoregulatory adjustments in renal vascular resistance $(4,6,7)$. The possible influence of the renin-angiotensin system on the base-line control setting of renal hemodynamics has received somewhat greater support $(3,8,9)$. Other reports have suggested that angiotensin might also be one important determinant of renal tubular absorptive function (10-13).

The precise role of the renin-angiotensin system in the mediation of the distal tubule-glomerulus feedback system (tubuloglomerular feedback system) signals also remains unclear. It was initially suggested by Thurau and co-workers (14) that the renin-angiotensin system could be primarily responsible for the media- 
tion of signals from the macula densa cells of the distal nephron to the vascular elements responsible for the altered vascular resistance responses. Support for this concept has been equivocal; some studies have failed to confirm the essential role of the renin-angiotensin system in the mediation of feedback signals, whereas others have demonstrated that this system must participate, at least indirectly. A preliminary report by Stowe et al. (15) suggested that the tubuloglomerular feedback mechanism was at least partially inhibited by a blockade of angiotensin II or converting enzyme.

The purpose of these experiments was to examine further the possible role of the renin-angiotensin system in single nephron and kidney function in a normal rat preparation. Although not without limitations, one way to achieve this objective was to evaluate the effect of acute inhibition of converting enzyme using the competitive converting enzyme inhibitor $(\mathrm{CEI})^{1}$ derived from Bothrops jaracara venom, SQ 20881 (E. R. Squibb \& Sons, Princeton, N. J.). Using this approach, the possible influence of intrarenal generation of angiotensin II on kidney and single nephron function might be determined.

In these experiments attention was focused on documenting the whole kidney clearance and hemodynamic responses after administration of CEI as related to simultaneously observed responses in single nephron filtration rate, absorptive function, and tubuloglomerular feedback activity. In addition to conventional clearance and micropuncture techniques, changes in tubuloglomerular feedback activity were assessed by three different techniques: estimates of single nephron glomerular filtration rate (SNGFR) based on tubule fluid collections from paired distal and proximal tubule segments of the same nephron, and by directly observing feedback-induced changes in proximal tubule stop flow pressure or SNGFR in response to alterations in late proximal tubule microperfusion rate. Single nephron absorptive function was assessed with paired tubular fluid collections before and after CEI administration.

\section{METHODS}

Experiments were performed on Sprague-Dawley rats weighing between 210 and $260 \mathrm{~g}$. Animals were maintained on a complete rat chow diet (Wayne Lab Blox, Allied Mills, Inc.,

\footnotetext{
${ }^{1}$ Abbreviations used in this paper: ATF, artificial tubular fluid; BP, blood pressure; CEI, converting enzyme inhibitor; $\mathrm{FE}_{\mathrm{Na}}$, fractional sodium excretion; GFR, glomerular filtration rate; $P_{\text {in }}$, plasma inulin concentration; $P_{\mathrm{Na}}$, plasma sodium concentration; RBF, renal blood flow; SNGFR, single nephron GFR; $S N G F R_{\text {dist }}$, SNGFR estimated from distal tubule fluid collections; SNGFR $_{\text {prox }}$, SNGFR estimated from proximal tubule fluid collections; $T_{F}$ in, tubular fluid inulin concentration; $U_{\text {in }}$, urine inulin concentration; $U_{N a}$, urine sodium concentration; $\dot{\mathrm{V}}$, urine flow rate.
}

Chicago, Ill.) containing 0.15 meq $\mathrm{Na}^{+} / \mathrm{g}$, and allowed free access to food and water. Anesthesia was induced with pentobarbital sodium (Nembutal, $50 \mathrm{mg} / \mathrm{kg}$ i.p.; Abbott Laboratories, North Chicago, Ill.), and maintained with small doses given intravensouly. Animals were prepared for micropuncture on a thermostatically controlled, heated table surface. A tracheostomy was performed, and three small polyethylene catheters were inserted into one external jugular vein for administration of anesthetic and infusion of solutions. An arterial cannula was inserted into the femoral artery. Arterial blood pressure was continuously measured with a transducer (model P-23 Dc, Statham Medical Instruments, Hato Ray, Puerto Rico) and recorded on a Grass recorder (model 5, Grass Instrument Co., Quincy, Mass.). The left kidney was isolated through a transverse, subcostal incision and placed in a small plastic cup; the ureter was catheterized; and the renal artery was isolated from adjacent structures. In 15 rats, an electromagnetic flow probe (model EP 401.5, Carolina Medical Electronics Inc., King, N. C., $1.5 \mathrm{~mm}$ circumference) was placed on the renal artery to allow direct and continuous measurement of renal blood flow. The flowmeter was calibrated in vitro with timed collection of whole blood, and verified in vivo using the para-aminohippuoric acid extraction technique as reported by Arendshorst et al. (4). Mechanical zero flow was checked by momentarily occluding the renal artery in every experiment.

The kidney surface was superfused with warm $\left(38^{\circ} \mathrm{C}\right)$ isotonic saline from the tip of a quartz rod light conductor. An inulin solution $(7.5 \mathrm{~g} / \mathrm{dl}$ in $150 \mathrm{mM} \mathrm{NaCl}$, Polyfructosan, Laevosan Gesellshaft, Linz, Austria) was administered as a priming dose of $1 \mathrm{ml}$ followed by an infusion at $20 \mu \mathrm{l} / \mathrm{min}(1.2$ $\mathrm{ml} / \mathrm{h}$ ). Control period measurements were initiated $20 \mathrm{~min}$ later. Each control period consisted of two 30-min urine collections with femoral arterial blood samples obtained in heparinized tubes at the midpoint of each urine collection. Micropuncture protocols were conducted simultaneously with clearance collection periods. After the control period, a priming dose of $3 \mathrm{mg} / \mathrm{kg}$ of CEI in $0.5 \mathrm{ml}$ of $155 \mathrm{mM} /$ liter $\mathrm{NaCl}$ was given intravenously in $3 \mathrm{~min}$. The priming dose was followed by an infusion of $3 \mathrm{mg} / \mathrm{kg}$ per h CEI in $155 \mathrm{mM} / \mathrm{liter}$ $\mathrm{NaCl}$ given at $10 \mu \mathrm{l} / \mathrm{min}(0.6 \mathrm{ml} / \mathrm{h})$ and the inulin solution was changed to $15 \mathrm{~g} / \mathrm{dl}$ given at $10 \mu \mathrm{l} / \mathrm{min}(0.6 \mathrm{ml} / \mathrm{h})$. An additional $20 \mathrm{~min}$ were allotted to achieve a steady-state condition, and the protocol as described for the control period was repeated. In addition to the blood samples for polyfructosan determination taken during the clearance periods, femoral arterial blood samples $(200 \mu \mathrm{l})$ were obtained from seven rats in each protocol at the end of the control period and 20 min after administration of CEI for the determination of plasma renin activity.

In six animals, tubular fluid samples for the determination of SNGFR were collected from paired distal and proximal superficial nephron sites before and after administration of CEI. Downstream tubular segments were identified visually with injections of small volumes $(\cong 5-10 \mathrm{nl})$ of artificial tubular fluid (ATF) stained with $0.25 \%$ fast green (Fast Green FCF, J. T. Baker Chemical Co., Phillipsburg, N. J.) into early proximal segments. The ATF solution contained $141 \mathrm{meq} /$ liter sodium, $5 \mathrm{meq} / \mathrm{liter}$ potassium, $124 \mathrm{meq} / \mathrm{liter}$ chloride, $26 \mathrm{meq} / \mathrm{liter}$ bicarbonate, and $4 \mathrm{meq} / \mathrm{liter}$ calcium. The stained solution was injected through a 4- to $6-\mu \mathrm{m}$ Diam pipette placed in a random proximal tubule allowing identification of downstream, late proximal, and early distal superficial tubule segments of that nephron. After identification of downstream loops, a superficial segment of the early distal tubule of the same nephron was punctured with an oil-filled pipette of 6- to 8- $\mu \mathrm{m}$ Diam tip, an oil block of 5-6 Diam tubule was injected, and tubular fluid was 
quantitatively collected for 5-10 min. Immediately after the distal tubule fluid collection, a late proximal segment of the same nephron was punctured, and a timed, quantitative collection of 3-4-min duration was obtained downstream from the identification pipette. The proximally placed identification pipette remained in place upstream during both collections. Detection of any extravasation of green-tinted ATF at the site of the proximal identification pipette disqualified that tubule pair, although detectable leaks were infrequent. After completion of collections, pipette tips were filled with a small amount of mineral oil to prevent evaporative losses.

Hydrostatic pressures in the kidney were measured in 14 animals with a servo-nulling micropressure device (model 900, W-P Instruments Inc., New Haven, Conn.). Micropressure pipettes were filled with $1 \mathrm{M} \mathrm{NaCl}$, slightly tinted with fast green. Pipette tip sizes were 4- to 6- $\mu \mathrm{m}$ Diam, and tip resistances were $0.8-1.2 \mathrm{M} \Omega$. The reference side of the micropressure circuit consisted of a $\mathrm{KCl}$-agar bridge, from the peritoneal cavity, to $3 \mathrm{M} \mathrm{KCl}$ in which a reference $\mathrm{Ag}: \mathrm{AgCl}$ electrode was immersed. Micropressures were continuously recorded on the Grass recorder. Calibration checks of the micropressure system were obtained before and after each experiment.

Microperfusion studies measuring stop-flow pressure (SFP) responses were done in 14 animals. Several proximal loops of the same nephron were identified with a proximally placed pipette containing the ATF solution with $0.25 \%$ fast green. A wax block (16) was injected into the tubule at the site of the identification pipette with a Wells microdrive unit (Trent Wells, Inc., South Gate, Calif.). The micropressure pipette was then inserted upstream from the wax block to record proximal tubule SFP. A 4- to $6-\mu \mathrm{m}$ Diam perfusion pipette containing the ATF solution, driven by a nanoliter microperfusion pump (W. Klotz, Physiology Institut, Munich, W. Germany) mounted on a micromanipulator, was inserted into a superficial loop of the same proximal tubule downstream from the wax block. The perfusion pump was calibrated in vivo and in vitro (17) with isotopic techniques; the design of the device allowed a built-in voltage generator to serve as the perfusion rate monitor. The perfusion pump pipette was inserted with the pump at zero flow, a maneuver that did not alter the continuously recorded proximal SFP. SFP was continuously recorded while perfusion rate was increased. When perfusion rate was altered, proximal SFP was recorded for a period of 3-5 min, and then the pump rate was changed to a new setting. The 3 - to 5-min delay was always adequate for 15- to 30-sec pump lag time, the feedback response time, and the achievement of a plateau SFP recording. The actual feedback responses could occur within $15-20 \mathrm{~s}$ as was observed when the perfusion pipette was inserted into some tubules with the pump already set at a high perfusion rate. The feedback perfusion protocol consisted of SFP recordings at perfusion rates of $0,5,10,15,20$, 30 , and $40 \mathrm{nl} / \mathrm{min}$ altered in random sequence in each tubule. Zero perfusion rate SFP was reassessed after every second perfusion rate change and recovery to the initial SFP value was always $\pm 2 \mathrm{~mm} \mathrm{Hg}$. Each of the perfusion experiments consisted of measurement of SFP at least once at each perfusion rate in two or more different tubules in each period. In eight animals, the feedback responses were assessed in an initial control period and then reassessed after converting enzyme inhibition. In six additional animals the opposite sequence was used by administering CEI in an initial experimental period. Feedback responses were assessed and then the CEI infusion was terminated. After allowing $\mathbf{4 0} \mathrm{min}$ for the decay of the enzyme inhibition, the responses of SFP to alterations in late proximal perfusion rate were reevaluated. This reversal of the sequence of the experimental protocol obviated possible systematic, timedependent artifacts in the SFP-feedback perfusion responses.

A separate series of experiments in six animals examined the effects of a similar feedback-perfusion protocol on changes in SNGFR before and during CEI infusion. In these studies the nephron was identified and blocked with wax as described for the SFP-perfusion studies. However, instead of continuously measuring proximal tubule SFP, multiple timed collections of tubular fluid were obtained allowing determination of SNGFR at late proximal tubule microperfusion rates of 0,10 , and $30 \mathrm{nl} / \mathrm{min}$. The responses of two or more different tubules were evaluated during each period.

Tubular fluid sample volumes (nanoliters) were measured in a precalibrated, constant-bore quartz glass capillary with a slide comparator (Gaertner Scientific Co., Chicago, Ill.). A microfluorometric method (18) was used to determine tubular fluid inulin concentration $\left(\mathrm{TF}_{\mathrm{in}}\right)$. Urine samples were collected under oil in small tared containers, and urine volumes were determined gravimetrically. Femoral arterial blood samples $(150 \mu \mathrm{l})$ were collected in small polyethylene containers containing heparin ( $5 \mathrm{U}$ U. S. Pharmacopeia). Inulin concentration in plasma $\left(\mathrm{P}_{\text {in }}\right)$ and urine $\left(\mathrm{U}_{\text {in }}\right)$ was measured with a semimicroanthrone technique (19). Urine and plasma sodium concentrations $\left(\mathrm{U}_{\mathrm{Na}}\right.$ and $\mathrm{P}_{\mathrm{Na}}$ ) were determined by flame photometry. SNGFR, measured in nanoliters per minute, was computed by multiplying tubular fluid to plasma inulin ratios $\left[(\mathrm{TF} / \mathrm{P})_{\text {in }}\right]$ by volume flow rates (nanoliters per minute). Kidney glomerular filtration rate (GFR) (measured in milliliters per minute) was similarly computed from $(U / P)_{\text {in }}$ concentrations and urine flow rate (microliters per minute). The product of sodium concentration in urine $\left(U_{\mathrm{Na}}\right)$ and urine flow rate $(\mathrm{V})$ gave sodium excretion rate, and fractional sodium excretion ( $\mathrm{FE}_{\mathrm{Na}}$, percentage) was calculated from $(\mathrm{U} / \mathrm{P})_{\mathrm{Na}} \cdot 100$ divided by $(\mathrm{U} / \mathrm{P})_{\mathrm{in}}$.

Blood samples $(200 \mu \mathrm{l})$ were obtained for plasma renin activity in iced tubes containing EDTA (disodium edenate, $1 \mathrm{mg}$ EDTA $/ \mathrm{ml}$ of blood). The tubes were immediately centrifuged and the plasma was decanted and frozen. Renin activity was determined in duplicate with 3-h incubation times by radioimmunoassay (Squibb Kit, E. R. Squibb \& Sons.). The technique used was a microadaptation of the method of Haber et al. (20). Generation of angiotensin I was documented to be linear with time during the 3-h incubation. Plasma renin is reported as nanograms of angiotensin I times milliliters plasma times hours of incubation.

Values for each period for each animal were averaged, and overall mean values were derived from mean values for each experiment. Observations from each period in each series of experiments were analyzed with a paired $t$ test. Significance was accepted as a $P$ value of $<0.05$.

\section{RESULTS}

The effectiveness of the converting enzyme blockade given in a dose of $3 \mathrm{mg} / \mathrm{kg}$ on the peripheral and renal vascular receptors is shown in Fig. 1. Before CEI infusion, test doses of 50 and $100 \mathrm{ng}$ of angiotensin I in volumes of $100 \mu \mathrm{l}$ of saline resulted in marked transient rises in systemic blood pressure (BP) and simultaneous decreases in renal blood flow $(\mathrm{RBF})$. After CEI administration, the vascular effects of as much as $150 \mathrm{ng}$ of angiotensin $\mathrm{I}$ in the same volume did not result in increases in arterial BP or perceptible decreases in RBF. This pattern of CEI blockade of the effects of angiotensin I was observed in all animals 


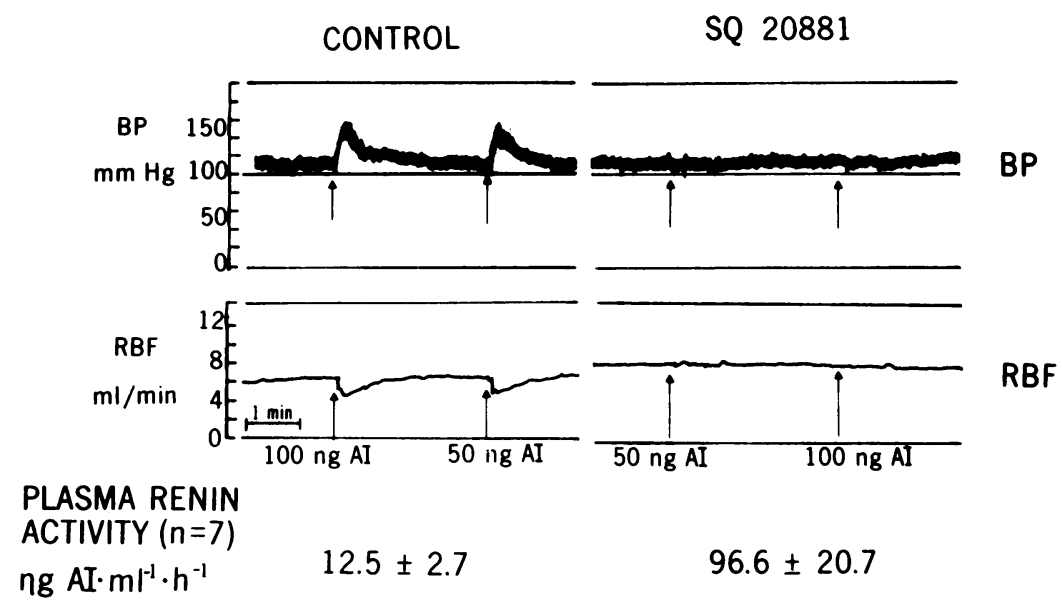

FIgURE 1 Converting enzyme blockade. The chart recordings demonstrate systemic BP $(\mathrm{mm}$ $\mathrm{Hg}$, top panel), and $\mathrm{RBF}$ (ml/min, bottom panel) responses to test injections of 50 and $100 \mathrm{ng}$ of angiotensin I (AI) before (left) and after (right) administration of CEI. Plasma renin activity before (left, mean \pm SEM) and after (right) SQ 20881 are shown below the tracing panels.

examined. Infusion of angiotensin I in doses of 10, 50, and $100 \mathrm{ng} / \mathrm{min}$ for as long as $60 \mathrm{~min}$ during the administration of CEI failed to elicit any perceptible change in RBF or arterial BP. In seven animals in which duplicate samples were measured in both periods, plasma renin activity increased from $12.5 \pm 2.7$ to $96 \pm 21 \mathrm{ng}$ angiotensin $\mathrm{I} / \mathrm{ml}$ per h during CEI ( $P$ $<0.025)$.

Clearance data from 15 experiments in which CEI was administered after control period measurements are shown in Fig. 2. GFR increased significantly from $1.08 \pm 0.05$ to $1.26 \pm 0.05 \mathrm{ml} / \mathrm{min}$. Urine flow increased from a control value of $4.8 \pm 0.9$ to $7.4 \pm 1 \mu \mathrm{l} / \mathrm{min}$. Absolute $\mathrm{Na}^{+}$excretion increased 10 -fold from $107 \pm 37$ to $1,235 \pm 318 \mathrm{neq} / \mathrm{min}$ during CEI. Because the increase in GFR was of much smaller magnitude, fractional excretion of $\mathrm{Na}^{+}\left(\mathrm{FE}_{\mathrm{Na}+}\right)$ increased from $0.03 \pm 0.01$ to $0.42 \pm 0.12 \%(P<0.005)$. Potassium excretion rate also increased during administration of CEI from $997 \pm 121$ to $1,451 \pm 181 \mathrm{neq} / \mathrm{min}(P<0.05)$. The mean values reported for the CEI period are the average of two clearance periods, and no consistent differences were observed from the first to the second clearance period.

Hemodynamic data obtained in the same 15 animals are shown in Fig. 3. Arterial BP decreased slightly but significantly from $127 \pm 2$ to $122 \pm 3 \mathrm{~mm} \mathrm{Hg}(P$ $<0.05)$. RBF increased from $6.7 \pm 0.4$ to $7.5 \pm 0.5 \mathrm{ml} / \mathrm{min}$ $(P<0.05)$. Similar to the clearance data, the increases in RBF after CEI were stable throughout both of the experimental clearance periods. Hematocrit decreased from $49 \pm 1$ to $46 \pm 1$ vol $\%(P<0.01)$. Because of the decreases in arterial hematocrit as well as the significant increases in absolute RBF, renal plasma flow increased from $3.6 \pm 0.2$ to $4.1 \pm 0.3 \mathrm{ml} / \mathrm{min}(P<0.001)$.
Although renal plasma flow was increased, the simultaneous increase in GFR was essentially proportional resulting in unchanged whole kidney filtration fraction from $0.29 \pm 0.02$ to $0.30 \pm 0.02$. Proximal tubule freeflow pressure was $14.0 \pm 0.4 \mathrm{~mm} \mathrm{Hg}$ and was not significantly altered by CEI. Similarly, peritubular capillary pressure was unchanged from $10.2 \pm 0.3 \mathrm{~mm}$ $\mathrm{Hg}$ before and $10.6 \pm 0.2 \mathrm{~mm} \mathrm{Hg}$ after administration of CEI.

SNGFR data from six animals are presented in Table I. Paired collections from proximal and distal tubule segments were obtained from 14 nephrons in the control period and from 17 nephrons during CEI infusion.

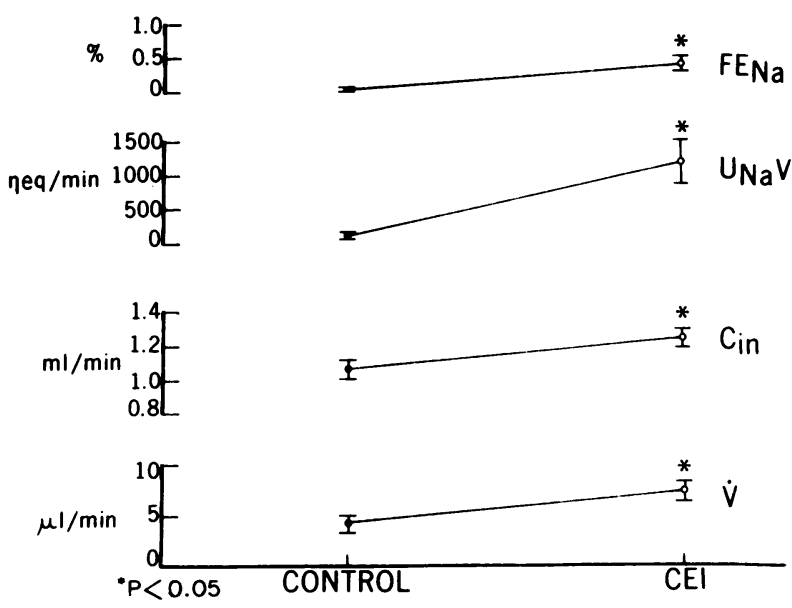

FIGURE 2 Clearance data. $\mathrm{FE}_{\mathrm{Na}}$, absolute sodium excretion $\left(\mathrm{U}_{\mathrm{Na}} \mathrm{V}\right)$, glomerular filtration rate $\left(\mathrm{C}_{\mathrm{in}}\right)$, and $\dot{\mathrm{V}}$ are shown as mean values \pm SEM, before and after CEI in 15 animals. The average kidney weight of 12 animals in this series of experiments was $0.98 \pm 0.02 \mathrm{~g}$. *Significance of $P<0.05$. 


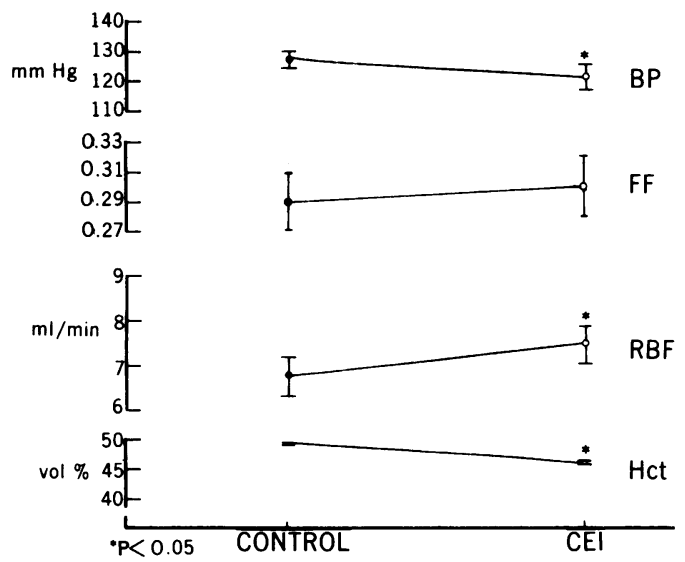

FIgURE 3 Hemodynamic data. BP, kidney filtration fraction (FF), RBF, and arterial hematocrit (Hct) are shown as mean values \pm SEM before and after CEI in the same 15 animals as Fig. 2. *Significance of $P<0.05$.

During the control period, there was a significant difference between SNGFR as estimated from proximal tubule fluid collections $\left(\mathrm{SNGFR}_{\text {prox }}\right)$ and SNGFR based on distal tubule fluid collections $\left(\mathrm{SNGFR}_{\mathrm{dist}}\right)$. Although both average $\mathrm{SNGFR}_{\text {prox }}$ and $\mathrm{SNGFR}_{\text {dist }}$ increased slightly after CEI, only the increase in SNGFR $_{\text {dist }}$ achieved statistical significance $(P<0.025)$. Although the average change in SNGFR $R_{\text {dist }}$ (Table I) was small, the consistency of the observed increase in SNGFR, shown in Fig. 4, allowed the achievement of statistical significance. As shown in Table I, the difference between SNGFR values measured at proximal and distal tubule sites was $6.0 \pm 1.6 \mathrm{nl} / \mathrm{min}$ during the control period and was unchanged during the CEI infusion, $5.7 \pm 1.8 \mathrm{nl} / \mathrm{min}$. Mid-proximal volume flow rates and proximal $(\mathrm{TF} / \mathrm{P})_{\text {in }}$ ratios were also unaltered. However, an increase in absolute volume delivery to the early distal tubule puncture site from $5.7 \pm 0.6$ to $7.9 \pm 1.0 \mathrm{nl} / \mathrm{min}$ was observed. The effects of the increases in volume flow rates at the early distal tubule collection sites were partially offset by slight decreases in mean $(\mathrm{TF} / \mathrm{P})_{\text {in }}$, thus explaining the proportionally smaller increment in SNGFR based on collections from distal tubules.

On the premise that $\mathrm{SNGFR}_{\text {dist }}$ provides the more representative estimate of $\operatorname{SNGFR}(17,21)$, changes in proximal absorption were based on SNGFR $_{\text {dist }}$ and proximal $(\mathrm{TF} / \mathrm{P})_{\text {in }}$ data. Absolute proximal absorption was $8.6 \pm 1.3 \mathrm{ml} / \mathrm{min}$ in the control period and was not changed during infusion of CEI; fractional absorption was also unchanged from $31 \pm 4 \%$ (Table II).

Although absolute volume delivery to the distal puncture site was increased after CEI infusion, absolute volume absorption by the loop and proximal tubule beyond the puncture site was unchanged after CEI, from $12.6 \pm 1.2$ to $12.8 \pm 1.2 \mathrm{nl} / \mathrm{min}(P>0.10)$. The fraction of the load delivered to the late proximal tubule and loop of Henle that was absorbed appeared to decrease from $69 \pm 3$ to $61 \pm 3 \%$ but did not achieve statistical significance. The tubular fluid samples obtained at the early distal micropuncture sites revealed significantly increased absolute volume delivery, from $5.7 \pm 0.6$ to $7.9 \pm 1.0 \mathrm{nl} / \mathrm{min}$ and an increased fraction of the filtered volume from $0.19 \pm 0.02$ to $0.27 \pm 0.03$ delivered to those sites during infusion of CEI. The fraction of the filtered volume absorbed upstream from the early, accessible distal tubule puncture site was reduced from $0.81 \pm 0.02$ to $0.73 \pm 0.03$ although the absolute volume absorbed was not altered by CEI. These absorptive alterations appear to be the result of slight increases in the rate of filtrate formation and subtle alterations in proximal tubule, loop of Henle, or early inaccessible distal tubule absorption rather than a specific effect on one tubule segment.

In 14 experiments, the sensitivity of the tubuloglomerular feedback mechanism was assessed by evaluating the responses of SFP to changes in distal nephron perfusion rate (Figs. 5 and 6, Table III) from

TABLE I

Results of Paired Micropuncture Collections from Proximal and Distal Tubule Sites in Six Animals

\begin{tabular}{lccccc}
\hline & \multicolumn{2}{c}{ Control (14) } & & \multicolumn{2}{c}{ CEI (17) } \\
\cline { 2 - 3 } \cline { 5 - 6 } & Proximal & Distal & & Proximal & Distal \\
\hline$\dot{V}, n l / m i n$ & $22.5 \pm 1.7$ & $5.7 \pm 0.6$ & & $25.0 \pm 2.8$ & $7.9 \pm 1.0^{*}$ \\
$(\mathrm{TF} / \mathrm{P})_{\text {in }}$ & $1.53 \pm 0.09$ & $5.11 \pm 0.6$ & & $1.69 \pm 0.19$ & $4.76 \pm 0.55$ \\
SNGFR, $n l / m i n$ & $32.9 \pm 1.8$ & $26.8 \pm 1.8$ & & $34.5 \pm 2.5$ & $28.9 \pm 1.2^{*}$ \\
$\Delta$ SNGFR, nl/min $\$$ & \multicolumn{2}{c}{$6.0 \pm 1.6^{*}$} & & \multicolumn{2}{c}{$5.7 \pm 1.8^{*}$} \\
\hline
\end{tabular}

Number of tubule pairs examined in each period appear in parentheses.

* Significant paired comparisons $(P<0.05)$.

$\$$ Paired difference in SNGFR measured at proximal nephron sites, distal nephron sites. 


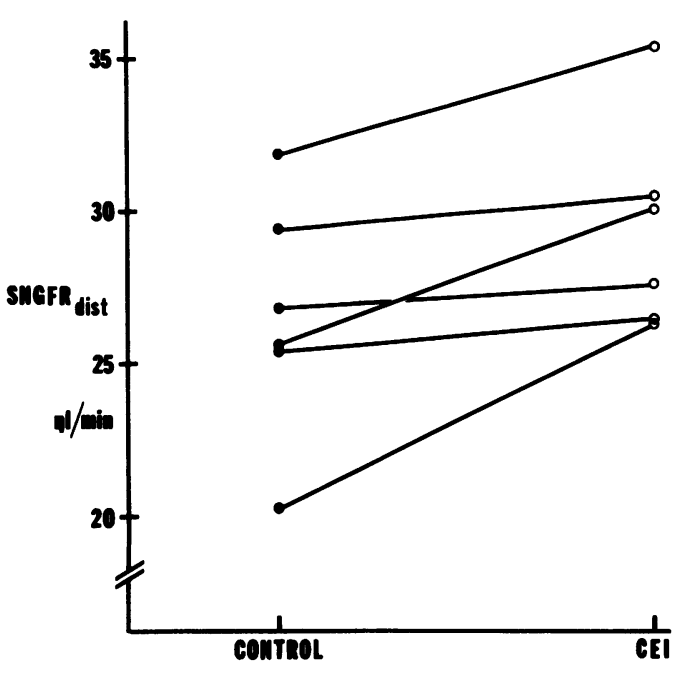

FIGURE 4 Paired SNGFR responses before and after CEI. SNGFR estimated from distal tubule fluid collections (SNGFR $_{\text {dist }}, \mathrm{nl} / \mathrm{min}$ ) is shown for each of six animals. Control observations (O) were obtained before, and CEI observations $(O)$ were obtained during converting enzyme blockade.

late proximal tubule microperfusion sites. Fig. 5 shows the results of eight experiments in which the control observations were made before administration of CEI, and Fig. 6 shows the results of six experiments where the control observations were made after dissipation of the CEI given in the initial period. Be-

\section{TABLE II}

Segmental Reabsorption Data: Puncture Site

\begin{tabular}{lcc}
\hline & Control & CEI \\
\hline & mean \pm SEM & mean \pm SEM \\
& $26.8 \pm 1.8$ & $28.9 \pm 1.2$ \\
SNGFR $_{\text {dist }}, n l /$ min $^{*}$ & & \\
Late proximal & $0.31 \pm 0.04$ & $0.29 \pm 0.06$ \\
Fractional absorption & $0.69 \pm 0.04$ & $0.71 \pm 0.06$ \\
Fractional delivery & $8.6 \pm 1.3$ & $8.2 \pm 1.6$ \\
Absolute absorption, $n l / m i n$ & $18.2 \pm 1.4$ & $20.7 \pm 1.8$ \\
Absolute delivery, $n l / m i n$ & & \\
Loop & & \\
Fractional absorption & $0.69 \pm 0.03$ & $0.61 \pm 0.03$ \\
Absolute absorption, $n l / m i n$ & $12.6 \pm 1.2$ & $12.8 \pm 1.2$ \\
& & \\
Early distal & & \\
Fractional absorption & $0.81 \pm 0.02$ & $0.73 \pm 0.03 \ddagger$ \\
Fractional delivery & $0.19 \pm 0.02$ & $0.27 \pm 0.03 \ddagger$ \\
Absolute absorption, $n l / m i n$ & $21.1 \pm 1.7$ & $20.9 \pm 1.0$ \\
Absolute delivery, $n l / m i n$ & $5.7 \pm 0.6$ & $7.9 \pm 1.0 \ddagger$ \\
\hline
\end{tabular}

Data were computed from the same observations of the six animals referred to in Table $I$.

* SNGFR $_{\text {dist }}$, SNGFR measured at distal micropuncture sites. \$ Paired changes from control period observations are significant $(P<0.05)$.

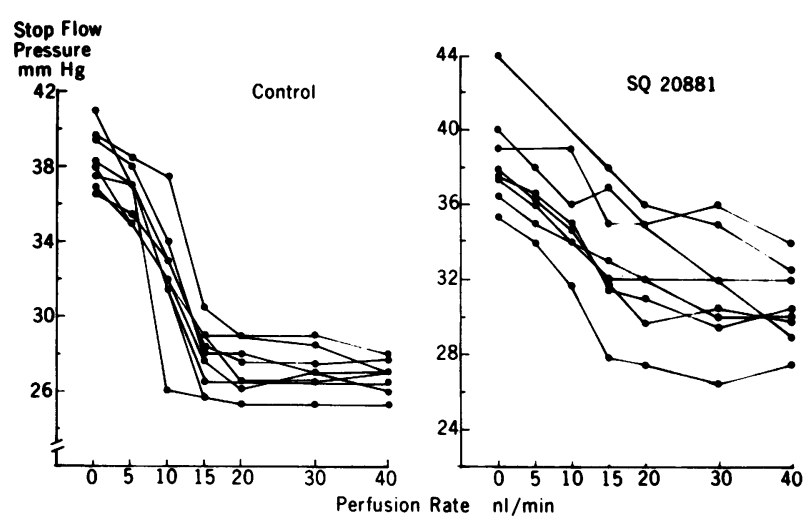

Figure 5 Tubuloglomerular feedback responses. Proximal tubule SFP is plotted as the average value for each animal, as late proximal perfusion rate was randomly changed in eight animals. Control observations (left) were obtained before administration of CEI (right).

cause the sequence of administration did not affect the results, the data for all 14 experiments were pooled and are shown in Table III. In the control period, changes in late proximal tubule perfusion rate resulted in nonlinear decreases in SFP; at maximum perfusion rate, the decreases in SFP averaged $11.2 \pm 0.4 \mathrm{~mm} \mathrm{Hg}$. Significant decreases in SFP were observed with increments in perfusion rate from 0 to 5 , 5 to 10,10 to 15 , and 15 to $20 \mathrm{nl} / \mathrm{min}$; further increases in perfusion rate from 20 to 30 , or 30 to 40 $\mathrm{nl} / \mathrm{min}$ did not result in additional decrements in SFP. The SFP values at zero perfusion rate were not different from control during infusion of CEI but the magnitude of SFP responses to distal perfusion was significantly attenuated. During administration of CEI, increases in perfusion rate to the maximum, $40 \mathrm{nl} / \mathrm{min}$,

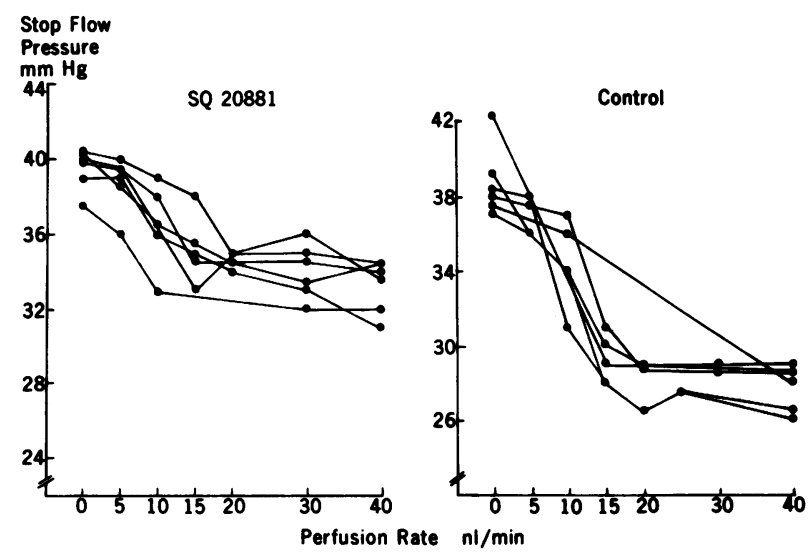

Figure 6 Tubuloglomerular feedback responses. Proximal tubule SFP is plotted as the average value for each animal as late proximal perfusion rate was randomly changed in six animals. Control observations (right) were obtained after dissipation of CEI (left). 
TABLE III

SFP Feedback Perfusion Studies before and after CEI

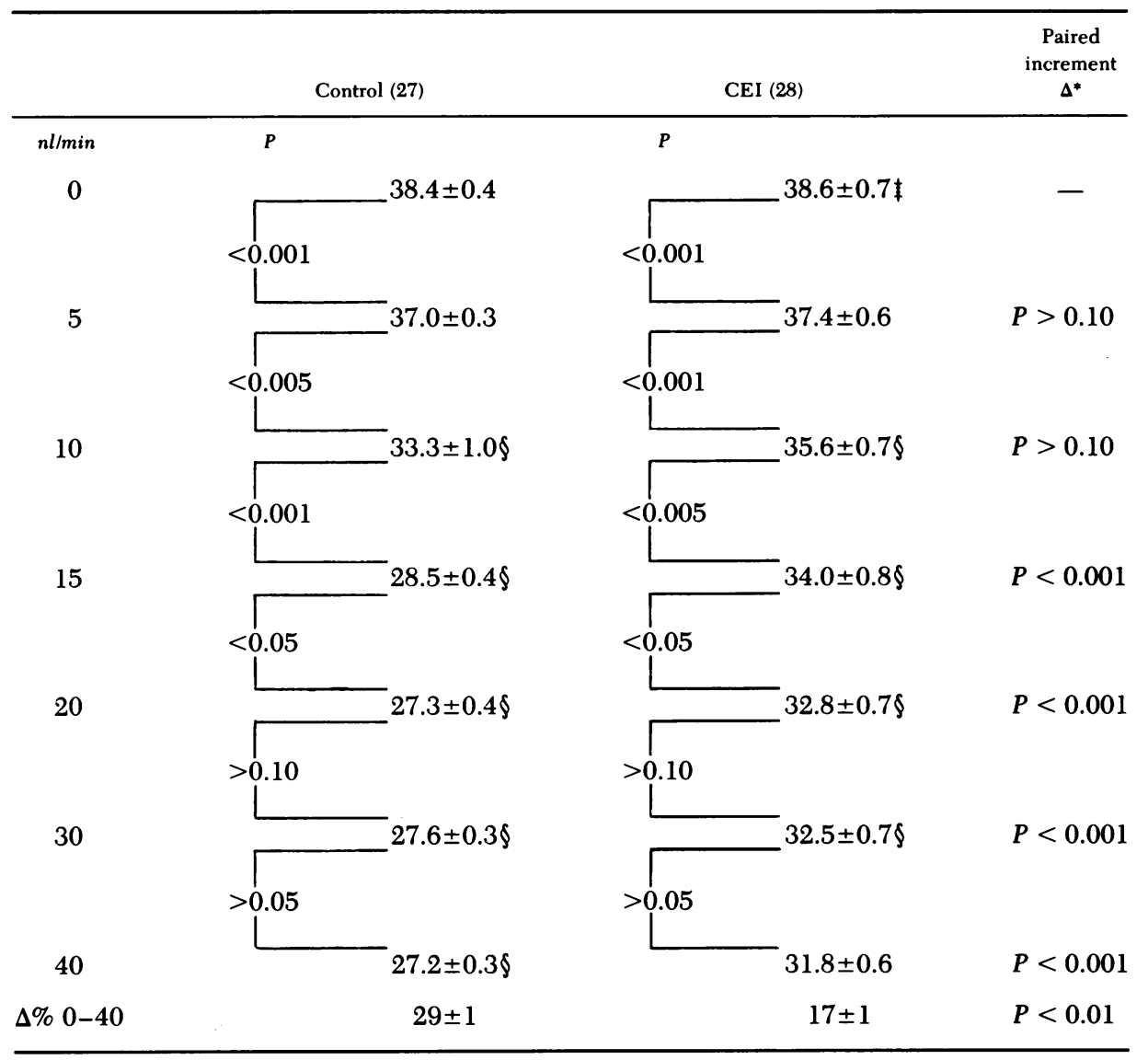

The table shows SFP in millimeters of mercury (mean \pm SEM) as late proximal perfusion rate was randomly changed. ATF was used in all perfusions. Number of tubules studied in 14 rats appear in parentheses. In eight animals the control measurements were obtained before CEI, and in six animals the control measurements were obtained after allowing dissipation of CEI.

* The paired increment $\Delta$ significances were tested by comparing the 0 to $x_{1} \mathrm{nl} / \mathrm{min}$ perfusion rate-induced changes in SFP from control to those observed with CEI.

$\$ P>0.10$, paired comparison of SFP at zero perfusion rate from control to CEI periods.

$\S P<0.05$, paired comparison of SFP at given perfusion rate to SFP at zero perfusion rate.

decreased SFP from $38.6 \pm 0.7$ to $31.8 \pm 0.6 \mathrm{~mm} \mathrm{Hg}$. This decrease in SFP of $6.7 \pm 0.5 \mathrm{~mm} \mathrm{Hg}$ was significantly less than the $11.2 \pm 0.4 \mathrm{~mm} \mathrm{Hg}$ decrease in SFP observed over the same perfusion interval in the control periods. When comparisons are expressed as percentage change in SFP as perfusion rate was changed from 0 to $40 \mathrm{nl} / \mathrm{min}$, SFP was decreased by $29 \pm 1 \%$ in the control period compared with $17 \pm 1 \%$ after CEI administration. The significant difference in magnitude of the maximum feedback-induced responses in SFP achieved before and after infusion of CEI indicates that overall tubuloglomerular feedback responsiveness was depressed. However, the pattern of SFP responses to incremental changes in perfusion rate after administration of CEI was not greatly different. Significant changes in SFP were observed with each step change in perfusion rate except the intervals $20-30$ and 30-40 $\mathrm{nl} / \mathrm{min}$. Nevertheless, the actual changes in SFP at the various perfusion rates were significantly less during CEI infusion (Table III). The SFP responses from 0 to $15 \mathrm{nl} / \mathrm{min}$ and from $0 \mathrm{nl} / \mathrm{min}$ to all higher perfusion rates were significantly attenuated during CEI infusion.

The six experiments assessing the changes in SNGFR in response to alterations in late proximal tubule microperfusion rate before and during infusion of CEI are summarized in Table IV. During control conditions, proximal tubule volume flow and SNGFR both decreased slightly, but significantly, when perfusion into late proximal tubules was increased from 0 to $10 \mathrm{nl} / \mathrm{min}$. In contrast, the de- 
TABLE IV

SNGFR-Feedback Perfusion Studies before and during Administration of CEI

\begin{tabular}{|c|c|c|c|c|c|c|c|c|c|c|c|}
\hline & \multicolumn{11}{|c|}{ Perfusion rate } \\
\hline & \multicolumn{3}{|c|}{$0 \mathrm{nl} / \mathrm{min}$} & \multicolumn{3}{|c|}{$10 \mathrm{nl} / \mathrm{min}$} & \multicolumn{3}{|c|}{$30 \mathrm{nl} / \mathrm{min}$} & \multicolumn{2}{|c|}{$\Delta 0-30 \mathrm{nl} / \mathrm{min}$} \\
\hline & $\mathrm{V}^{*}$ & $(\mathrm{TF} / \mathrm{P})_{\mathrm{in}}{ }^{*}$ & SNGFR* & $\mathrm{V}$ & $(\mathrm{TF} / \mathrm{P})_{\text {!n }}$ & SNGFR & $\mathrm{v}$ & $(\mathrm{TF} / \mathrm{P})_{\mathrm{in}}$ & SNGFR & SNGFR & Percent \\
\hline $\begin{array}{l}\text { Control } \\
\text { CEI }\end{array}$ & $17.0 \pm 1.7$ & $1.99 \pm 0.34$ & $29.1 \pm 1.9$ & $14.9 \pm 1.7 \ddagger$ & $2.07 \pm 0.55$ & $25.0 \pm 2.3 \ddagger$ & $8.0 \pm 1.01$ & $2.11 \pm 0.54$ & $14.1 \pm 1.7 \ddagger$ & $-15.0 \pm 1.2 \ddagger$ & $-52.3 \pm 4.2 \ddagger$ \\
\hline (SQ 20881) & $24.0 \pm 2.5$ & $1.61 \pm 0.21$ & $34.3 \pm 1.7$ & $21.8 \pm 2.8$ & $1.67 \pm 0.19$ & $32.2 \pm 2.6$ & $14.2 \pm 0.9 \rrbracket$ & $1.67 \pm 0.17$ & $22.7 \pm 2.0 \ddagger$ & $-11.3 \pm 1.3^{*} \ddagger$ & $-32.2 \pm 2.7 \downarrow \S$ \\
\hline
\end{tabular}

* The table summarizes changes in proximal tubule volume flow (V), tubular fluid/plasma inulin ratios [(TF/P) in], and SNGFR during control periods and during infusion of CEI (SQ 20881) in six animals.

$\downarrow P<0.05$, paired comparison of $\mathrm{V}$ or $\mathrm{SNGFR}$ at given perfusion rate to $0 \mathrm{nl} / \mathrm{min}$ perfusion rate of the same period.

$\S P<0.01$, paired comparison of change in SNGFR or percentage change in SNGFR in response to change in perfusion rate from 0 to $30 \mathrm{nl} / \mathrm{min}$ from control to CEI periods.

creases in volume delivery and SNGFR were not significant over the same perfusion interval during CEI infusion (Table IV). The responses to increases in perfusion rate from 0 to $30 \mathrm{nl} / \mathrm{min}$ were also of greater magnitude during control than during CEI infusion; SNGFR was decreased by $15.0 \pm 1.2$ and $11.3 \pm 1.3 \mathrm{nl} / \mathrm{min}$, respectively $(P<0.01)$. When the changes in SNGFR are expressed as percentage change from the $0 \mathrm{nl} / \mathrm{min}$ perfusion rate value, increases in late proximal perfusion rate from 0 to $30 \mathrm{nl} / \mathrm{min}$ resulted in decreases in SNGFR of $52 \pm 4 \%$ during the control period and $32 \pm 3 \%$ during converting enzyme blockade $(P<0.001)$.

\section{DISCUSSION}

The present results provide further data concerning hemodynamic and tubular responses to the administration of CEI. Specifically, these studies focus on possible alterations in tubuloglomerular feedback activity occurring as a consequence of the intrarenal inhibition of converting enzyme. In initial observations, we documented that converting enzyme inhibition resulted in virtually complete blockade of the vascular effects of injected doses of angiotensin I. Presumably, near complete blockade of intrarenal formation of angiotensin II also occurred, although this aspect of converting enzyme inhibition is more difficult to establish.

At the whole kidney level, administration of CEI resulted in modest but consistent increases in RBF and GFR. Because approximately proportional changes in both GFR and RBF were observed, filtration fraction was not altered. The hemodynamic changes were accompanied by a doubling of urine flow and an impressive 10-fold increase in sodium excretion even though arterial pressure decreased slightly. Because the micropuncture measurements of proximal tubular and peritubular capillary pressure failed to indicate significant changes, it would seem that the hemodynamic changes were not of sufficient magnitude to affect the pressures of superficial nephron structures.
However, measurements of SNGFR from both proximal and distal tubule collection sites suggested small increases in SNGFR; specifically the increase in SNGFR $_{\text {dist }}$ was statistically significant although it was proportionally less than the increase in kidney GFR. In agreement with previous studies $(17,21)$, SNGFR $_{\text {prox }}$ was found to be consistently higher than SNGFR $_{\text {dist }}$ and this difference was maintained during CEI administration. As observed in a previous study examining the effects of plasma volume expansion (17), the maintenance of the SNGFR difference based on paired collections from proximal and distal tubules might suggest an unaltered status of the tubuloglomerular feedback mechanism, the putative system responsible for these differences. However, when the maintenance of the SNGFR $_{\text {prox }}-S_{N G F R}$ dist difference is considered in the context of the $40 \%$ increase of distal tubule fluid delivery observed during converting enzyme blockade, it would seem that some alteration in the distal tubule feedback mechanism must have occurred. Without some decrease in sensitivity of the feedback system, a greater distal volume delivery should decrease SNGFR as measured from distal tubule sites and result in differences in SNGFR between the two sites of greater magnitude. In fact, as noted above, SNGFR $_{\text {dist }}$ was actually increased.

The distal nephron microperfusion experiments demonstrated that, under control conditions, small but significant changes in SFP and SNGFR were observed as late proximal perfusion rate was altered in the range of 0 to $15 \mathrm{nl} / \mathrm{min}$. These observations extend those of our earlier study (17) and, furthermore, provide an explanation for the observed differences in SNGFR based on proximal and distal tubule fluid collections. In some previous reports (22), a significant difference in SFP and SNGFR between conditions of zero distal volume flow rate and distal flow rates in the normal range was not observed consistently. It has been suggested, therefore, that the tubuloglomerular feedback system is responsive primarily to in- 
creases in flow rate above the normal range. The present observations, however, do support the concept that feedback activity is also responsive to alterations in flow rates below the normal range as suggested by the data of Muller-Suur et al. (23). It should also be noted that microperfusion of the late proximal tubule with artificial solutions at a given flow rate may not provide an identical stimulus to the feedback receptor as normal tubular fluid. Therefore, it is hazardous to attempt precise and quantitative extrapolations from the SFP and SNGFR feedback responses to the SNGFR data based on mid-proximal and early distal tubule fluid collections in nonperfused tubules. For the present, then, only the qualitative conclusion can be made that significant decreases in SFP and SNGFR do occur when perfusion rate is increased to values within the normal range.

The observations that the decrease in proximal tubule SFP or SNGFR at maximal perfusion rate was diminished support the concept that the sensitivity of the feedback mechanism is attenuated by CEI administration. Increases in volume delivery rates in the range of those observed for normal conditions (10-15 $\mathrm{nl} / \mathrm{min}$ ) resulted in less change in SFP and SNGFR during infusion of CEI. Thus, the slight but significant renal vasodilation observed after administration of CEI can be explained on the basis of a decreased sensitivity of the feedback mechanism, allowing less than expected vascular resistance for the given higher distal tubule volume flow rate.

These results complement earlier studies reported by Schnermann and co-workers (24) and a recent report from our laboratory (17), demonstrating that feedbackinduced responses in early proximal flow rate (24) or proximal tubule SFP (17) were decreased in states of acute or chronic extracellular fluid or plasma volume expansion. The attenuation of feedback activity after plasma volume expansion may be the result of reduced intrarenal renin activity or circulating angiotensin II. In the present experiments the attenuation of tubuloglomerular feedback activity would seem to be singularly the result of the CEI. Because some of the experiments were conducted in the reverse sequence, time-dependent decay of feedback activity was obviated. The most likely mechanism responsible for this depressed status of feedback sensitivity is intrarenal inhibition of the formation of angiotensin II or perhaps reduced circulating levels of angiotensin II. In this context, the data support the conclusion that converting enzyme in the in vivo rat kidney is inhibited with SQ 20881. This is at variance with a recent report that in in vitro preparations of renal tissue converting enzyme was not inhibited by SQ 20881 (25). However, CEI is also known to potentiate the effects of bradykinin and possibly other active kinin species (26-28) and, therefore, the possibility of significant accumulation of such substances cannot be excluded. Although the role of possible kinin accumulation remains disputed $(29,30)$, the preliminary report by Stowe et al. (15) wherein tubuloglomerular feedback activity was equally attenuated in protocols using CEI as compared with those in which the angiotensin II receptor antagonist Saralasin $\left[\mathrm{Sar}^{1}, \mathrm{Ile}^{8}\right]$ angiotensin II, Norwich-Eaton Pharmaceuticals, Norwich, N. Y.) was administered (15), would support the possibility that the primary effect resulted from reduction in the renal action of the renin-angiotensin system on tubuloglomerular feedback sensitivity. Other, perhaps less likely, alternative mechanisms include alterations in renal nerve tone, circulating catecholamines, or some nonspecific vasodilator effect of CEI.

One of the principal reasons for conducting these experiments was to test the hypothesized role of the renin-angiotensin system in the mediation of the tubuloglomerular feedback responses as suggested by Thurau (14). The failure to demonstrate complete inhibition of the feedback responses with CEI would seem to indicate that mediation of feedback signals does not depend singularly on the integrity of the renin-angiotensin system. However, as suggested in the past, it is possible that the demonstrably complete vascular blockade is not an adequate index of the integrity of the local, intrarenal renin-angiotensin system or mediation of the feedback responses. Nevertheless, the demonstration of vascular blockade seems to be the best physiological index available. To the extent that complete local blockade was achieved, the present results indicate that the renin-angiotensin cascade is one component of the system necessary for full expression of tubuloglomerular feedback activity. It is also possible that angiotensin could modify baseline vascular resistance response relationships or could affect tubular absorptive function at the macula densa, in either case explaining the attenuated tubuloglomerular feedback responses to increases in distal delivery.

As mentioned, one finding of considerable interest was the marked natriuresis during CEI infusion. Recent studies have shown that low doses of angiotensin II may be antinatriuretic $(13,31)$, and it is therefore attractive to associate the reduced angiotensin II generation and the natriuresis observed in these experiments. It should be clearly noted, however, that only a small fraction of the increment in a filtered load of sodium appeared in the urine during CEI infusion, documenting increased absolute tubular absorption during conditions of impaired angiotensin II generation.

Of interest is the speculative possibility that the 
absorptive alterations and the attenuated tubuloglomerular feedback activity might be more directly linked. Fractional absorptive function was depressed in tubule segments before and possibly involving the early distal tubule puncture site. It would seem plausible that the depressed absorptive capacity might also alter the sensor mechanism involved in initiation of the feedback signal such as has been demonstrated for the potent loop diuretics $(32,33)$.

\section{ACKNOWLEDGMENTS}

The authors thank Dr. Thomas E. Andreoli for reviewing the manuscript and Ms. Becky Smith and Mrs. Pam Burkart for their stenographic assistance. The authors acknowledge Dr. Z. Horowitz and E. R. Squibb \& Sons, Princeton, N. J., for the generous gift of SQ 20881.

Financial support for these studies was in part derived from National Institutes of Health grant HLB 18426 and from a Veteran's Administration research grant. Intramural support was provided by the University of Alabama Nephrology Research and Training Center and the Alabama Urological Research and Rehabilitation Center.

\section{REFERENCES}

1. Peters, G., and J. P. Bonjour. 1971. Renal effects of renin and angiotensin. In The Kidney, Morphology, Biochemistry, Physiology. C. Rouiller and A. F. Muller, editors. Academic Press Inc., New York. 4: 81-154.

2. Navar, L. G., and H. G. Langford. 1973. Effects of angiotensin on the renal circulation. In Handbook of Experimental Pharmacology. O. Eichler, A. Farah, H. Herken, and A. D. Welch, I. H. Page, and F. M. Bumpus, editors. Springer-Verlag, Berlin. 37: 455-474.

3. Thurston, H., and J. H. Laragh. 1975. Prior receptor occupancy as a determinant of the pressor activity of infused angiotensin II in the rat. Circ. Res. 36: 113-117.

4. Arendshorst, W. J., W. F. Finn, and C. W. Gottschalk. 1975. Autoregulation of blood flow in the rat kidney. Am. J. Physiol. 228(1): 127-133.

5. Kaloyanides, G. J., R. D. Bastron, and G. F. DiBona. 1974. Impaired autoregulation of blood flow and glomerular filtration rate in the isolated dog kidney depleted of renin. Circ. Res. 35: 400-412.

6. Belleau, L. J., and L. E. Earley. 1967. Autoregulation of renal blood flow in the presence of angiotensin infusion. Am. J. Physiol. 213: 1590-1595.

7. Potkay, S., and J. Gilmore. 1973. Autoregulation of glomerular filtration rate in renin depleted dogs. Proc. Soc. Exp. Biol. Med. 143: 508-513.

8. Hollenberg, N. K., W. R. Chenitz, D. F. Adams, and G. H. Williams. 1974. Reciprocal influence of salt intake on adrenal glomerulosa and renal vascular responses to angiotensin II in normal man. J. Clin. Invest. 54: 34-42.

9. Brunner, H. R., P. Chang, R. Wallach, J. E. Sealey, and J. H. Laragh. 1972. Angiotensin II vascular receptors: their avidity in relationship to sodium balance, the autonomic nervous system, and hypertension. J. Clin. Invest. 51: 58-67.

10. Barraclough, M. A., N. F. Jones, and C. D. Marsden. 1967. Effect of angiotensin on renal function in the rat. Am. J. Physiol. 212(5): 1153-1157.

11. Lowitz, H. D., K. O. Stumpe, and B. Ochwadt. 1969. Micro- puncture study of the action of angiotensin II on tubular sodium and water reabsorption in the rat. Nephron. 6: 173-187.

12. Johnson, M. D., and R. L. Malvin. 1977. Stimulation of renal sodium reabsorption by angiotensin II. Am. J. Physiol. Renal Fluid Electrolyte Physiol. 1(4): F298F306.

13. Harris, P. J., and J. A. Young. 1977. Dose-dependent stimulation and inhibition of proximal tubular sodium reabsorption by angiotensin II in the rat kidney. Pflügers Arch. Eur. J. Physiol. 367: 295-297.

14. Thurau, K. 1974. Intrarenal action of angiotensin. In Angiotensin (Handbook of Experimental Pharmacology). I. H. Page and F. M. Bumpus, editors. Springer-Verlag, Berlin. 37: 475-489.

15. Stowe, N. T., J. Schnermann, and M. Hermle. 1979. Feedback regulation of filtration rate during pharmacologic interference with the renin-angiotensin and adrenergic systems in rats. Kidney Int. 15: 473-486.

16. Gutsche, H. U., R. Muller-Suur, U. Hegel, K. Hierholzer, and S. Luderitz. 1975. A new method for intratubular blockade in micropuncture experiments. Pflügers Arch. Eur. J. Physiol. 354: 197-202.

17. Ploth, D. W., J. Rudulph, C. E. Thomas, and L. G. Navar. 1978. Renal and tubuloglomerular feedback responses to plasma expansion in the rat. Am. J. Physiol. Renal Fluid Electrolyte Physiol. 4(2): F156-F162.

18. Vurek, G., and S. Pegram. 1966. Fluorometric method for the determination of nanogram quantities of inulin. Anal. Biochem. 16: 409-419.

19. Fuhr, J., J. Kaczmarczyk, and C. D. Kruttgen. 1970. Eine einfache colorimetrische Methode zur Inulinbestimmung fur Nieren-Clearance-Untersuchungen bei Stoffwechselgesunder und Diabetikern. Klin. Wochenschr. 33: 729730 .

20. Haber, E., T. Koerner, L. B. Page, B. Kliman, and A. Pernode. 1969. Application of a radioimmunoassay for angiotensin I to the physiologic measurements of plasma renin activity in normal human subjects. J. Clin. Endocrinol. Metab. 29: 1349-1359.

21. Ploth, D. W., J. Schnermann, H. Dahleim, M. Hermle, and E. Schmidmeier. 1977. Autoregulation and tubuloglomerular feedback in normotensive and hypertensive rats. Kidney Int. 12: 253-267.

22. Schnermann, J., E. Persson, and B. Agerup. 1973. Tubuloglomerular feedback: nonlinear relation between glomerular hydrostatic pressure and loop of Henle perfusion rate. J. Clin. Invest. 52: 862-869.

23. Muller-Suur, R., H-U. Gutsche, K. F. Samwer, W. Oelkers, and K. Hierholzer. 1975. Tubuloglomerular feedback in rat kidneys of different renin contents. Pflügers Arch. Eur. J. Physiol. 359: 33-56.

24. Schnermann, J., M. Hermle, E. Schmidmeier, and H. Dahleim. 1975. Impaired potency for feedback regulation of glomerular filtration rate in DOCA escaped rats. Pflügers Arch. Eur. J. Phsyiol. 358: 325-338.

25. Baranowski, R. L., C. Westenfelder, and N. A. Kurtzman. 1979. Renal angiotensin I converting enzyme differs from that of lung and is not inhibited by captoril (SQ 14225). Clin. Res. 27: 494A.(Abstr.)

26. Engle, S. L., T. R. Schaeffer, B. I. Gold, and B. Rubin. 1972. Inhibition of pressor effects of angiotensin I and augmentation of depressor effects of bradykinin by synthetic peptides. Proc. Soc. Exp. Biol. Med. 140: 240-244.

27. Erdos, E. G. 1976. Conversion of angiotensin I to angiotensin II. Am. J. Med. 60: 749-759. 
28. Erdos, E. G. 1976. The kinins, a status report. Biochem. Pharmacol. 25: 1563-1569.

29. Jaeger, P., R. K. Ferguson, H. R. Brunner, E. J. Kirchertz, and H. Gavras. 1978. Mechanism of blood pressure reduction by teprotide (SQ 20881) in rats. Kidney Int. 13: 289-296.

30. Thurston, H., and J. D. Swales. 1978. Converting enzyme inhibitor and saralasin infusion in rats. (Evidence for an additional vasodepressor property of converting enzyme inhibitor.) Circ. Res. 42(5): 588-592.

31. Malvin, R. L., and A. J. Vander. 1967. Effects of angio- tensin infusion on renal function in the unanesthetized rat. Am. J. Physiol. 213(5): 1205-1208.

32. Bell, P. D., C. Thomas, R. H. Williams, and L. G. Navar. 1978. Filtration rate and stop flow pressure feedback responses to nephron perfusion in the dog. Am. J. Physiol. Renal Fluid Electrolyte Physiol. 3(2): F154F165.

33. Wright, F. S., and J. Schnermann. 1974. Interference with feedback control of glomerular filtration rate by furosemide, triflocin, and cyanide. J. Clin. Invest. 53: 16951708. 